\title{
MOOCS FOR BRIDGING THE SCHOOL - UNIVERSITY GAP
}

\author{
Ilaria Merciai, \& Ruth Kerr \\ Federica Weblearning Centre, University of Naples Federico II (Italy)
}

\begin{abstract}
This paper presents an update of the MOOC orientation strategy implemented by Federica Weblearning, the Centre for Innovation, Experimentation and Diffusion of Multimedia learning at the University of Naples, Federico II since January 2019 and already published in the same year. The adoption of a solid orientation strategy continues to be driven by the need to support students in their university choice and prepare them for the intellectual demands of university life and study. According to OECD, the number of graduates in Italy has increased in 2019 from $20 \%$ to $28 \%$ in the $25-34$ age range, and Italy has high numbers of post-graduate degree holders. However, as in the rest of the world, dropout rates in Italy continue to be high, currently standing at approximately $25 \%$ of registered students. The MOOC-based orientation strategy addresses possible ways of bridging the gap between school and university. The initial Federica meta-MOOC strategy provides a tool for helping students choose the right degree. Meta-MOOCs offer experiential chunks of real university courses, thus demonstrating content type, learning approach and expected levels of attainment. In 2020, the Federica Weblearning orientation offer has been extended via a new partnership with the CISIA inter-university consortium. This initiative focuses on MOOCs that fill in the knowledge gaps, providing preparatory courses in key areas where weaknesses have been identified to support students through first-year university exams, or indeed, university entrance tests. A further prong is currently being added to the overall Federica orientation strategy: MOOC activities to foster student awareness to deal with change positively, and adopt the path towards self-fulfilment.
\end{abstract}

Keywords: MOOCs, freshman orientation.

\section{Introduction - Degrees to plug the skills gap?}

Orientation is a crucial phase for school-leavers as they face major decisions about their future, and whether to aim for a university degree or not and, if so, in what subject. The global jobs market is a fast-changing and unpredictable place, and it is getting harder for students to choose a degree that will make them career-ready in a world where "8 - 9 percent of 2030 labour demand will be in new types of occupations that have not existed before" [McKinsey] and OECD statistics predict that " $15.2 \%$ of Italian workers may see their job being automated and another $35.5 \%$ may see it significantly overhauled in the next ten years" [OECD]. EU and OECD data confirm that demands from the jobs market are shifting towards more complex, non-routine tasks and non-cognitive skills as a result of digitalisation and globalisation. On average, shortages are the strongest in the "knowledge of Computers and Electronics followed closely by substantial demand for Judgment and Decision Making Skills and Verbal Abilities (written expression and comprehension and oral expression)" [OECD Skills for Jobs Database].

A recent World Economic Forum report stated that although Italy has good culture and civic literacy, critical thinking and problem-solving skills, its citizens have poor foundation skills, including literacy, numeracy, scientific and financial literacy. [World Economic Forum] And despite the need for increased digital skills in Italy, women continue to be under-represented in ICT education, with only 13\% of ICT students being female in Italy in 2016. [Eurostat]

School-leavers, both male and female, may well be tempted to try and choose a degree subject that aims, in some way, to plug one of these skills gaps. In Italy and elsewhere. On the other hand, the value of humanities degrees is also being re-recognised, as was recently evidenced by Microsoft executives amongst others: "as computers behave more like humans, the social sciences and humanities will become even more important... (as they) can teach critical, philosophical and ethics-based skills that will be instrumental in the development and management of AI solutions". [Business Insider] 


\section{Value of tertiary education}

Whichever department or subject area students choose, however, one thing still holds true. University degrees continue to be the main currency for the jobs market and, in general, increase a student's chances of employability. In America, for example, employment rates are $89 \%$ for students with a bachelors or higher degree compared to $59 \%$ for those without [NCES]. Italy is following this trend with educational attainment continuing to grow. More Italian students have MAs than in many other European countries and even though Italy still has a higher than EU average number of NEETs, people with degrees are less likely to be unemployed long-term. [OECD Education at a Glance]

Although many school-leavers are thus encouraged to think that a university degree is the best next step, statistics regarding drop-out rates and change of subject amongst university students would seem to indicate that a significant percentage of students continues to leave university without a degree. [Eurostat] This has a "scarring effect in the form of greater marginalisation and negative labor market outcomes" [Sosu, E.M., Pheunpha, P. 2019] and thus significant consequences for individuals, institutions and society. Although the reasons for university dropout are many and varied, "students' intellectual capability to cope with the academic demands of university study is one of the most significant risk antecedents consistently identified across the literature" [Sosu, E.M., Pheunpha, P. 2019]. And in Italy ANVUR reports that, for example, in Industrial Engineering, 19\% of students have abandoned their studies at 3 years from registration and $27 \%$ at 6 years, and overall, on a National level, dropout rates are at $12.2 \%$ for $3 \mathrm{yr}$ bachelors, at $5.9 \%$ for $2 \mathrm{yr}$ MAs and $7.5 \%$ for 5 or $6 \mathrm{yr}$ Combined degree programs, meaning an overall dropout rate of approx. 25\%. [Anvur]

\section{Effectiveness of MOOC-based orientation strategy}

We would like to argue that learning technologies can provide structured learning pathways with clearly mapped stages, engaging and relevant content that allows for flexible access and personalisation of learning, while predictive analytics can flag issues that help identify at-risk students. And that, therefore, a MOOC-based orientation strategy could be, as reported in our previous paper, an effective tool for:

a) raising awareness of degree content in different subject areas to enable school-leavers to make an informed choice, especially in popular degree subjects that are not necessarily included in school syllabuses, like psychology, law, engineering, communication sciences etc.). MOOC lessons also give a taste of the university classroom, with clear indications of expected performance and attainment levels via the accompanying assessment activities;

b) providing preparatory or remedial study content in specific areas to boost learning and fill the knowledge-gaps, thus reducing the possibility of students finding themselves unable to cope with the level of intellectual difficulty posed by university study.

The main areas for a MOOC strategy then are twofold: the first is to provide useful tools and links to help students choose the right degree for them. The second is to provide preparation for university study in the sense of "filling in the knowledge gaps" using specific subject MOOCs. A third prong of the strategy that is currently being proposed at Federica Weblearning is to use MOOCs to:

c) improve students' levels of self-knowledge and awareness, to render them more resilient in the face of the major changes that university and its associated study, as well as the future workplace, pose for them.

In all cases it would seem that orientation strategies require the support of the teacher for successful implementation. Already in 2014, the Italian Ministry for Education published national guidelines for lifelong orientation which recognised the important role that schools had in "helping people develop their own identity and make the right decisions regarding their personal and professional life, as well as facilitating the match between demand and supply in the jobs market". [Orizzonte Scuola] Many schools already had a Head of Orientation who is responsible for orientation initiatives and approaches, nominated as a result of a former Ministerial decree in 2004. The commitment of the teachers as disseminators and multipliers is central to the uptake of online learning initiatives like MOOCs, which might otherwise remain hidden on the Web.

\section{Institutional interest in MOOCs for schools}

There are signs that institutional interest in MOOCs for schools has continued since our last paper. The new European Commission President, Ursula von der Leyen, aims to update the Digital Education Action Plan and increase the use of MOOCs in the area of digital skills to "get Europe up to speed [Techcrunch] and the H2020 project UP2U aims to bridge the gap between secondary schools and higher education \& research by better integrating formal and informal learning scenarios and adapting both the 
technology and the methodology that students will most likely be facing in universities [UP2U] In the same period, the French national MOOC initiative, FUN, has significantly increased its Orientation offer. The FUN platform is now offering 31 orientation MOOCs of which 20 are new, fruit of the MOOCFOLIO project financed by the French Government [MOOCFOLIO] The aim is to enable students to " 1 ) choose the right degree 2) reinforce their knowledge and bridge the gap between school and university". The Italian EduOpen University Consortium has also now inserted a section on its homepage entitled Orientation, and offers 30 introductory courses in aspects of maths, physics, statistics, law and other popular university subject areas. On the other hand, the leading European and American OPMs that offered the university preparation initiatives we reported in our previous paper [Merciai I., Kerr R., 2019] (Futurelearn and edX) have made no further investment or effort in this area.

As reported in our previous paper [Merciai I., Kerr R., 2019], the Federica Web Learning Centre has been experimenting with the use of meta-MOOCs for bridging the gap between school and Higher education since 2019. These place the emphasis on the first of the main MOOC strategies identified above, that is, they offer chunks of the major degree courses offered at national level, and thus enable students to experience the university classroom and content and standards first-hand. The role of the teacher as multiplier was fundamental to the success of this project, as the initial point of contact was with individual class teachers who chose to adopt this series of orientation mini-MOOCs as a classroom activity and involved the class in the creation of their own digital artefacts as a project outcome. 8452 local students in the Naples area followed the meta-MOOC project in 2019.

\section{MOOCs as preparation for university entrance}

In a new extension to the Federica MOOC Orientation activity, and in line with the second of the main MOOC strategies identified above, the Federica Web Learning Centre has recently started a collaboration with CISIA (Consortium Interuniversity for Integrated Access Systems). The Cisia is a non-profit consortium, comprising 50 Italian Public universities, whose role is primarily to aid university access and orientation, by creating, administering and marking university admissions tests. Their role also includes the development of tools on the part of their consortium members, to plug freshmen knowledge gaps in a bid to reduce repeated failure in all-important modules of the course and thus reduce potential dropout rates. The MOOC initiative is a valuable addition to their toolbox.

The CISIA Federica Weblearning collaboration consists in offering specific online courses - on the Federica platform - to help students prepare for university entrance exams to those faculties where stringent selection procedures are in place. These MOOCs can also serve as remedial learning content for struggling first year students. The Italian Ministry for Universities and Research, first with the PLS and then with the POT projects (Plan for Science Degrees and Plan for Orientation and Tutoring) [MIUR] published open Calls to Universities to design and produce learning content for final year school students in the 6 disciplinary areas where gaps had been identified: Basic Maths; Physics; Chemistry; Biology; Logic; Text Analysis and Comprehension and Italian Language Skills. The design and development of MOOCs to improve baseline knowledge in these key areas is specifically mentioned in the Ministerial Decree. The aim is to boost interaction between schools and universities to improve levels of college readiness on the part of school-leavers and with the overall objective to:

- increase university enrolment rates;

- promote awareness in choice of degree;

- reduce dropout rates;

- support students in completing degrees within the recommended time-frame.

Within this Ministerial initiative, the CISIA consortium is committed to designing effective self-learning and self-assessment tools, and MOOCs will make a valuable contribution to this orientation and tutoring activity on their part. The Federica Weblearning/CISIA collaboration, which focuses on the production of new introductory MOOCs to improve baseline knowledge for better university access and performance, is already under way. It includes establishing guidelines for effective MOOC design and creation with a national committee of stakeholders. The first phase of the joint initiative saw the creation of a set of courses in Basic Mathematics for the following subject areas: Engineering and Science, Agricultural science, Economics and Pharmacy. Maths was identified by the universities and teachers involved in the project as being one of the most significant hurdles for students on these degree courses, and according to OECD statistics, Pisa performance for mathematics and science shows poor performance for Italy compared to its European counterparts. [PISA]

The design of the courses was aimed at a school-leaver audience and enables them to explore and clarify basic concepts in 10 lessons. Numerous videos, texts and formative assessments accompany the student through the theory and practice of functions, equations, logarithms, geometry and other fundamental aspects of maths for further science studies. 
Once the courses were ready, a two-pronged dissemination plan launched the initiative. Major stakeholders from both partner networks were invited to a Study Day on Technology Enhanced Learning where the courses were presented. This coincided with the launch of a dedicated page on the Federica platform www.federica.eu/cisia (April 2019) and on the CISIA platform that publicized the initiative and also provided access to the four Mathematics courses.

\section{Initial CISIA / Federica project results}

The initiative has met with success in terms of student numbers in the first 6 months of its lifespan. We report some of the more significant user data, updated to January 2020, in the table below. The data shows the success of a collaborative university network and results show a greater need for mathematics for Science and Engineering so far. The collaboration will continue in the forthcoming months.

Table 1

\begin{tabular}{|l|l|}
\hline CISIA users registered on the FEDERICA platform & $\begin{array}{l}19,919 \text { users registered on Federica.EU } \\
\text { via Single Sign On }\end{array}$ \\
\hline Numbers of students registered & 14,000 total registered users \\
\hline $\begin{array}{l}\text { Number of times a visitor accessed the Federica } \\
\text { platform via the project Landing Page }\end{array}$ & 45,683 \\
\hline Bounce rate & $14,56 \%$ \\
\hline
\end{tabular}

The Federica / CISIA collaboration will be extended in the forthcoming months.

\section{Future extension of MOOC strategy to vocational orientation}

In addition to the two routes towards orientation that Federica has already explored, and that we have presented here above, future work at the Centre will also focus on the third way; that of vocational orientation for students. The objective is to equip students with life skills that develop an awareness of self, and the changes that their lives will undergo as they enrol at university, and how this new level of understanding will enable them to achieve personal goals and fulfilment. This is one of the overall objectives of one of the most significant and wide-reaching POTS under way - that of Engineering, which involves 41 Universities. The University of Naples Federico II is heading this group, due to its research and teaching excellence in this area, and Federica Weblearning, as a consequence, will incorporate experimentation of this approach to orientation in future MOOC initiatives. A National Day of Study devoted to tools and ideas for vocational orientation, was already organised by Federico II in November 2019, touching on subjects like New directions for an inclusive and sustainable future; Policies, practices and pathways towards more active student orientation. ${ }^{1}$

\section{Conclusion}

A two-pronged MOOC strategy for Orientation has been implemented effectively by Federica Weblearning in the last twelve months: preparation for university choice via the Meta-MOOC initiative, and knowledge enhancement via the CISIA initiative. A forthcoming change of platform interface will give greater space and visibility to these orientation initiatives, that respond to the needs and expectations of the digital generation by speaking and using their language. These existing orientation activities will be reinforced and extended. New experimentation will move in tandem with the University Engineering POT, adding a possible third prong to the orientation strategy, that of vocational orientation and life skills.

\footnotetext{
1 "Giornata di studio sul tema: Strumenti dell'orientamento vocazionale per l'accesso agli studi universitari" organized in Nov. 2019, by the Polytechnic School of Federico II (Scuola Politecnica e delle Scienze di Base) http://www.scuolapsb.unina.it/index.php/9-inevidenza-highlights/743-giornata-di-studio-sugli-strumenti-di-orientamento-vocazionale
} 


\section{References}

Anvur, Rapporto biennale sullo stato del sistema universitario e della ricerca 2018. Retrieved January 13, 2020 from http://www.anvur.it/wp-content/uploads/2018/07/Sintesi_Rapporto2018_WEB.pdf

Business Insider, 2018, Microsoft's president says liberal arts majors are necessary for the future of tech. Retrieved January 13, 2020, from https://www.businessinsider.com/microsoft-president-says-techneeds-liberal-arts-majors-2018-1? IR $=\mathrm{T}$

Communication of Bicocca University MIUR Italian Ministry of Education PLS and POT projects. Retrieved January 13, 2020, from https://cspace.spaggiari.eu/pub/MIIT0018/Orientamento/2Attuazione_POT_PLS.pdf

Eurostat, Back Work beats study for 25\% of university drop-outs, 2018. Retrieved January 13, 2020 from https://ec.europa.eu/eurostat/web/products-eurostat-news/-/DDN-20180404-1).

Eurostat, Girls and women under-represented in ICT. Retrieved January 13, 2020, from https://ec.europa.eu/eurostat/web/products-eurostat-news/-/EDN-20180425-1

Merciai I., Kerr R., 2019, MOOCs as a Key Strategy for University Orientation in Education and New Developments 2019, ISSN: 2184-044X ISBN: 978-989-54312-5-0 2019

MOOCFOLIO project on FUN platform. Retrieved January 8, 2020 from https://www.mooc-orientation.fr

NCES, Retrieved January 13, 2020 from https://nces.ed.gov/programs/coe/indicator_cbc.asp

OECD, Education at a Glance. Retrieved January 13, 2020 from https://www.oecd.org/education/education-at-a-glance/

OECD, Skills for Jobs Database. Retrieved January 13, 2020, from https://skillspanorama.cedefop.europa.eu/en/news/oecd-skills-jobs-database-2018

OECD, The future of Work. How does Italy Compare. Retrieved January 13, 2020, from https://www.oecd.org/italy/Employment-Outlook-Italy-EN.pdf

Orizzonte Scuola, Il ruolo dei docenti nel percorso di orientamento universitario, 2019. Retrieved January 13, 2020 from https://www.orizzontescuola.it/il-ruolo-dei-docenti-nel-percorso-di-orientamentouniversitario-ecco-la-guida-alla-scelta-del-corso-di-laurea-di-edises/

PISA 2012 Results. Retrieved January 13, 2020, from https://www.oecd.org/italy/PISA-2012-resultsitaly.pdf

Sosu, E.M., Pheunpha, P., 2019, Trajectory of University Dropout: Investigating the Cumulative Effect of Academic Vulnerability and Proximity to Family Support Front. Educ., 12 February 2019 https://doi.org/10.3389/feduc.2019.00006

Techcrunch, Techdriven change. A Key Priority for new EC President. Retrieved January 8, 2020 from https://techcrunch.com/2020/01/07/tech-driven-change-a-key-priority-for-new-ec-president/

UP2U project. Retrieved January 8, 2020 from https://up2university.eu

World Economic Forum, The Future of Jobs Report 2018. Retrieved January 13, 2020, from https://www.weforum.org/reports/the-future-of-jobs-report-2018 